\title{
Study of maternal near miss and mortality in obstetrics in a tertiary care hospital
}

\author{
Pallavi G. Ninama, Ronak D. Karnavat, Shivani T. Siddhpura, Jil P. Karia*
}

Department of Obstetrics and Gynaecology, GMERS Medical College and Hospital, Sola, Ahmedabad, Gujarat, India

Received: 05 December 2021

Revised: 07 January 2022

Accepted: 10 January 2022

\section{*Correspondence:}

Dr. Jil P. Karia,

E-mail: jilkaria@gmail.com

Copyright: () the author(s), publisher and licensee Medip Academy. This is an open-access article distributed under the terms of the Creative Commons Attribution Non-Commercial License, which permits unrestricted non-commercial use, distribution, and reproduction in any medium, provided the original work is properly cited.

\begin{abstract}
Background: Maternal health is an important aspect for the development of any country in terms of increasing equity and reducing poverty. In 2009, WHO came up with clinical, laboratory and management criteria for identification of the maternal near miss cases. Aim of the current study was to determine the level of near-miss maternal morbidity and mortality due to severe obstetrical complications or maternal disease in a tertiary care hospital. Objectives of the study were to compare the relation of near miss events with that of maternal mortality and to see the trend of near miss events.

Methods: Cases were defined based on WHO criteria 2009. Study was conducted at GMERS Medical College and Hospital, Sola, Ahmedabad from 2020 to 2021. The study population were near miss cases and maternal deaths.

Results: During the period of audit there were a total of 6776 deliveries, 6434 live birth, 145 near miss and 36 maternal deaths.

Conclusions: Haemorrhage and hypertension are the leading cause of maternal near miss and maternal mortality in our hospital. As near miss indices represent quality of health care it should be represented in the national indices.
\end{abstract}

Keywords: Maternal near miss, Maternal mortality, Obstetrics

\section{INTRODUCTION}

Maternal health is an important aspect for the development of any country in terms of increasing equity and reducing poverty. MMR in the country has declined to 167 (2011-13) against a global MMR of 216 (2015). The number of maternal deaths stands reduced by $68.7 \%$. India's share among global maternal deaths has declined significantly to about $15 \%$ as per the MMEIG report. The process of maternal death review (MDR) has been institutionalized across the country both at facilities and in the community to identify not just the medical causes, but also some of the socio-economic, cultural determinants, as well as the gaps in the system which contribute to the delays causing such deaths. This is with the objective of taking corrective action at appropriate levels and improving the quality of obstetric care. ${ }^{1}$
Maternal near miss case is defined as "a woman who nearly died but survived a complication that occurred during pregnancy, childbirth, or within 42 days of termination of pregnancy". ${ }^{2}$ In 2009 , WHO came up with clinical, laboratory and management criteria for identification of these cases. In current study we aimed to determine the frequency of maternal near miss, maternal mortality and the maternal near miss to mortality ratio. Our second objective was to determine the nature of near miss and compare the causes of near miss to maternal mortality.

\section{METHODS}

An audit of maternal near from the years 2020 and 2021 was studied. Ours is a tertiary care hospital. It is also a referral centre for both public and private hospitals in the 
district of Ahmedabad. The hospital provides 24-hour emergency service, antenatal care and obstetric services for both low and high-risk cases, high dependency unit (HDU) in labour room complex and 24-hour blood bank.

\section{Study type, location}

Current study is a descriptive analytical conducted at GMERS medical college and civil hospital, Sola, Ahmedabad, Gujarat, India.

\section{Inclusion and exclusion criteria}

High risk cases were identified and those who met WHO 2009 near miss criteria were selected. It includes a set of clinical, laboratory and management-based criteria. This is a descriptive analysis and retrospective review with study duration of two years. Those who complicated after 42 weeks of termination of pregnancy were excluded. The following near miss indices were calculated: maternal near miss (MNM) ratio: Number of maternal near miss cases per 1000 live birth. Maternal near miss: mortality ratio: Ratio of maternal near miss and maternal mortality. Higher ratio indicated better care, statistical analysis was done using Microsoft excel.

\section{RESULTS}

During the period of audit there were a total of 6776 deliveries, 6434 live birth, 145 near miss and 36 maternal deaths. Characteristics of women with near miss and mortality are shown in (Table 1).

Table 1: Characteristics of maternal near miss and mortality.

\begin{tabular}{|lllllll|}
\hline Characteristics & Near miss $(\mathbf{N}=\mathbf{1 4 5})$ & & Maternal deaths $(\mathbf{N}=36)$ & Total \\
\hline Year & $\mathbf{2 0 2 0}$ & $\mathbf{2 0 2 1}$ & Total & $\mathbf{2 0 2 0}$ & $\mathbf{2 0 2 1}$ & Total \\
\hline Age (years) & $26.5 \pm 4.75$ & $25.7 \pm 4.6$ & $26.0 \pm 4.7$ & $27.5 \pm 4.8$ & $27.2 \pm 4.4$ & $27 \pm 4.5$ \\
\hline Parity N (\%) & & & & & & \\
\hline Primipara & $40(57.14)$ & $45(60)$ & 85 & $7(43.75)$ & $11(55)$ & 18 \\
\hline Multipara & $30(42.86)$ & $30(40)$ & 60 & $9(56.25)$ & $9(45)$ & 18 \\
\hline Gestational age (weeks) N (\%) & & & & & \\
\hline $1-12$ & $10(14.28)$ & $11(14.67)$ & 21 & $3(18.75)$ & $2(10)$ & 5 \\
\hline $13-28$ & $6(8.57)$ & $8(10.67)$ & 14 & $2(12.5)$ & $1(5)$ & 3 \\
\hline$>28$ & $40(57.14)$ & $44(58.67)$ & 84 & $7(43.75)$ & $10(50)$ & 17 \\
\hline Postnatal & $14(20)$ & $12(16)$ & 26 & $4(25)$ & $7(35)$ & 11 \\
\hline Causes N (\%) & & & & & & \\
\hline Haemorrhage & $26(37.14)$ & $32(42.67)$ & 48 & $4(25)$ & $5(25)$ & 9 \\
\hline Hypertension & $26(37.14)$ & $22(29.33)$ & 58 & $2(12.5)$ & $3(15)$ & 5 \\
\hline Sepsis & $9(12.85)$ & $11(14.67)$ & 20 & $2(12.5)$ & $3(15)$ & 5 \\
\hline Cardiac & $2(2.86)$ & $4(5.33)$ & 6 & $2(12.5)$ & $1(5)$ & 3 \\
\hline Indirect & $7(10)$ & $6(8)$ & 13 & $2(12.5)$ & $2(10)$ & 4 \\
\hline
\end{tabular}

Table 2: Comparison of near miss events and primary causes of maternal death.

\begin{tabular}{|llllll|}
\hline & Near miss & \multicolumn{2}{l}{ Mortality } & \multicolumn{2}{l}{ Near miss/ 1000 live birth } \\
\hline Diagnosis & $\mathbf{2 0 2 0}$ & $\mathbf{2 0 2 1}$ & $\mathbf{2 0 2 0}$ & $\mathbf{2 0 2 1}$ & \\
\hline Hypertensive disorders of pregnancy & 26 & 22 & 4 & 5 & 7.46 \\
\hline Severe pre-eclampsia & 8 & 6 & 1 & 1 & - \\
\hline Eclampsia & 12 & 12 & 2 & 3 & - \\
\hline HELLP & 6 & 4 & 1 & 1 & - \\
\hline Severe haemorrhage & 26 & 32 & 2 & 3 & 9.01 \\
\hline Early pregnancy & & & & & \\
\hline Ectopic pregnancy & 2 & 2 & 1 & 1 & - \\
\hline Abortion & 1 & 4 & 1 & 2 & - \\
\hline Late pregnancy & & & & & \\
\hline Abruption & 3 & 5 & 1 & 2 & - \\
\hline PPH & 20 & 21 & 3 & 4 & - \\
\hline Sepsis & 9 & 11 & 2 & 3 & 3.12 \\
\hline Cardiac & 2 & 4 & 2 & 1 & 0.93 \\
\hline Indirect & 7 & 6 & 2 & 2 & 2.02 \\
\hline Total & 70 & 75 & 16 & 20 & 22.53 \\
\hline
\end{tabular}


Primipara $(57.14 \%)$ was mostly in the near miss group. Majority of the patients were in the third trimester $(57.14 \%)$ when the near miss event occurred. The number of maternal death in the postpartum period were quite high $(35 \%)$ in 2021 when compared to the near miss group (16\%). Maternal near miss incidence ratio is 22.53 near miss/1000 live births. Maternal near miss to mortality ratio is $4.02: 1$. Among the causes of maternal near miss events, hemorrhage $(40 \%)$ was the leading cause followed by hypertension (33\%). Third amongst the group was sepsis followed by indirect and cardiac causes. The near miss cases and the maternal mortalities is shown in (Table 2). The near miss index for each event is given. The near miss index is highest for severe haemorrhage followed by hypertensive disorders of pregnancy.

\section{DISCUSSION}

Maternal Death has been used to represent the quality of health care. But in the present scenario, maternal near miss may take over maternal death to represent the quality of health care and hence should be given importance. WHO 2009 maternal near miss criteria incorporates both Mantel's and Waterson's criteria, hence it minimizes the chance of missing any near miss case.

A study by Jayarathnam et al represents near miss from a developed country and the results are as expected, $\mathrm{PPH}$, pre-eclampsia and sepsis are the major causes. ${ }^{3}$ In comparison, the percentage of haemorrhage were same but the near miss ratio is almost three times more in developing country (India) from developed country (Australia). Other countries like Nepal, Syria, Africa and Indonesia have shown similar trends in near miss. ${ }^{4-8}$

Sanju Kumari et al study indicated that the most common causes of MNM were haemorrhage (53.8\%), hypertensive disorders of pregnancy $(21.7 \%)$, medical disorders $(13.3 \%)$ and obstetric sepsis $(8.8 \%)$. Majority of Maternal deaths were due to direct obstetric causes $(71.8 \%)$. The most common direct causes for maternal deaths were hypertensive disorders of pregnancy (31.2\%). More number of women in the maternal death group $(34.3 \%$ versus $27.7 \%$ ) presented to the hospital with postpartum complications. $^{9}$ A study by Kamal et al indicated that Near-miss per 1000 delivery was 24\%. Maternal death to near miss ratio was 1:7.2. The leading causes of maternal near miss were hemorrhage $(42.5 \%)$ and hypertensive disorder of pregnancy (23.5\%) The morbidity was high in unbooked cases. ${ }^{10}$ Near-miss per 1000 delivery was $24 \%$. Maternal death to near miss ratio was 1:7.2. The leading causes of maternal near miss were hemorrhage $(42.5 \%)$ and hypertensive disorder of pregnancy $(23.5 \%)$ The morbidity was high in unbooked cases. $^{10}$

Singh et al study indicated that the maternal near-miss to mortality ratio (MNM: 1 MD) was 4:1, and the mortality index (MI) was $19.9 \%$. Haemorrhagic disorders were the leading cause (40.5\%) of MNM, followed by hypertensive disorders $(25.5 \%)$ and cardiac diseases $(14.4 \%)$. Similarly, both haemorrhage $(23.7 \%)$ and sepsis $(23.7 \%)$ were the leading causes of death followed by hypertensive disorders $(15.8 \%) .{ }^{11}$ Ours is a tertiary care hospital with most of the cases being referred in an already moribund state. The delays in referral are a major cause of maternal near miss and mortality. Delayed diagnosis, inappropriate transfer and inadequate utilization of resources might have been the cause of maternal morbidities and mortalities in our study. Along with increased awareness of one's own health, health education may help a lot in improving obstetric care.

\section{Limitations}

Limitation of current study was as ICU facilities were available few potentially life threatening conditions before becoming near miss might have been included in the study.

\section{CONCLUSION}

Haemorrhage and hypertensive disorders are the major causes of maternal near and maternal mortality. The trend of maternal near miss and maternal mortality has been the same in the two years under study. As maternal near miss indicates quality of health care, it is worth presenting in national indices.

\section{Funding: No funding sources \\ Conflict of interest: None declared \\ Ethical approval: Not required}

\section{REFERENCES}

1. Maternal and adolescent health care, annual report 2017-2018. Available at: https://main.mohfw.gov.in/ publications/annual-report-department-health-andfamily-welfare-2017-18. Accessed on 20 November 2021.

2. Roopa PS, Verma S, Rai L, Kumar P, Pai MV. Near miss obstetric events maternal deaths in a tertiary care hospital: an audit. J Preg. 2013;2013:393-8.

3. Jayaratnam S, De Costa C, Howat P. Developing an assessment tool for maternal morbidity 'near-miss'- a prospective study in a large Australian regional hospital. Aust N Z J Obstet Gynaecol. 2011;51(5): 421-5.

4. Shrestha NS, Saha R, Karki C. Near miss maternal morbidity and maternal mortality at Kathmandu Medical College Teaching Hospital. Kathmandu Univ Med J (KUMJ). 2010;8(30):222-6.

5. Almerie Y, Almerie MQ, Matar HE, Shahrour Y, Al Chamat AA, Abdulsalam A. Obstetric near-miss and maternal mortality in maternity university hospital, Damascus, Syria: a retrospective study. BMC Pregnancy Childbirth. 2010;10:65.

6. Oladapo OT, Sule-Odu AO, Olatunji AO, Daniel OJ. "Near-miss" obstetric events and maternal deaths in 
Sagamu, Nigeria: a retrospective study. Reprod Health. 2005;2:9.

7. Ali AA, Khojali A, Okud A, Adam GK, Adam I. Maternal near-miss in a rural hospital in Sudan. BMC Pregnancy Childbirth. 2011;11:48.

8. Adisasmita A, Deviany PE, Nandiaty F, Stanton C, Ronsmans C. Obstetric near miss and deaths in public and private hospitals in Indonesia. BMC Pregnancy Childbirth. 2008;8:10.

9. Kumari S, Umuziranenge I, Small M, van Roosmalen J. Maternal near miss and mortality in a tertiary care hospital in Rwanda. BMC Pregnancy Childbirth. 2015; 15:203.

10. Samarina K. A study of maternal near miss cases at tertiary medical college of Jharkhand, India. Int J
Reprod Contracept Obstet Gynecol. 2017;6(6):237580.

11. Singh V, Barik A. Maternal near-miss as a surrogate indicator of the quality of obstetric care: a study in a tertiary care hospital in eastern India. Cureus. 2017;13(1): e12548.

Cite this article as: Ninama PG, Karnavat RD, Siddhpura ST, Karia JP. Study of maternal near miss and mortality in obstetrics in a tertiary care hospital. Int J Reprod Contracept Obstet Gynecol 2022;11:473-6. 